result of delirium tremens; that is really in the system before they come in.

"2683. - You have no reason to think that the prison discipline acts upon them?-No; I have very carefully watched them, and I have had a large mass of figures got out to produce to you if you want them, but it is not 1 per cent., it is not a quarter of 1 per cent., and we have 8000 prisoners who went through the gaol last year."

Before concluding this brief paper it may perhaps be interesting and instructive to glance back along the century now about to expire and to compare the English prisons of 100 years ago with those of the present day. In 1795 convicts were herded together in hulks, in which no attempt was made to check the evils of association, and "vice, profanity, and demoralisation" ran riot. Great evils-among them the indiscriminate crowding together of prisoners - were still prevalent in the county and borough prisons, but the reports of John Howard had begun to alarm the national conscience, and justices were beginning to visit and inspect these prisons at periodical intervals. There were nearly 600 prisons in the United Kingdom. In many of them no attempts were made to divide the males from the females, gaol fever was still prevalent, and horrible scenes of wickedness were occasionally enacted. John Howard had made his final journey through Holland, Germany, Prussia, and Livonia to Russia and Lesser Tartary, and had been laid to rest at Cherson, in Russia, where his remains have lain undisturbed to the present day; he had travelled 60,000 miles, and it is believed that he spent from first to last $£ 30,000$ of his own money in the prosecution of his self-imposed duties. If he could now revisit this country he would find that each inmate of the local prisons has a cell of a capacity of about 800 cubic feet to himself, and that this cell, which is in the cleanest condition possible, is furnished with special arrangements for the withdrawal of used-up air and the supply of fresh air. $\mathrm{He}$ would observe that the furnishing of the cell, though not luxurious, is sufficient for the needs of the prisoner; and he would also observe that the prisoner is supplied with the necessary utensils, with good food, with abundance of water, with books, and with a bell-pull by means of which he can draw the attention of the officer of the ward. He would find that the food is sufficient and well prepared, that a well-arranged hospital js provided for the care and treatment of the sick, and that on the expiration of his sentence Discharged Prisoners' Aid Societies are ready to take him in hand and to assist him in making a fresh start in life. Although the prison system of the present day in this country, like other human institutions, may not be perfect, it may be questioned whether the next hundred years will witness evolutionary changes comparable to those that have taken place in British and Irish prisons since 1795. The next great step would seem to be the recoonition by society of its duties in the direction of the prevention of crime, and the discharge of its duties in such a manner as to convert the possible criminal into a useful member of the commonwealth. Whether the somewhat pessimistic doctrines of the criminal anthropologist be accepted as the basis of action, or the more hopeful view of those who regard a proclivity to the commission of crime as the natural outcome, in the majority of cases, of unfarourable surroundings from infancy upwards, there can be no doubt that the criminal elements in society may be largely reduced by such social reforms as the prevention of overcrowding, by attention to the details of sanitation, by judicious education, and by such training as will tend to eradicate habits of idleness. A distinctive feature in the character of the habitual criminal is a distaste for regular labour. The changes that are destined to take place in prison administration, and the measure in which society will interfere to prevent the genesis of the criminal during the next century, cannot, perhaps, be even roughly indicated, but it cannot be doubted that the good work initiated by John Howard will be continued in such manner and with such effect that some, at least, of the criminal classes will lose their characteristics as criminals, and will be finally absorbed into other classes of the social organisation.

St. Quintin-avenue, W.

Mr. George Mülter, of Ashley Down Orphan Houses, Bristol, reached his ninetieth birthday a few days ago, and has received numerous presents and congratulations from friends in all parts of the country.

\section{CASE OF HÆMATOCELE SUPERVENING ON AN ABORTION.}

By J. O'REILLY, M.B. Dubl., M.CH., SURGEON-LIEUTENANT-COLONEL, ARMY MEDICAL STAFF.

THe subject of this case was a woman about twenty-eight years of age, strong and healthy. She had been married four months and was about three months advanced in pregnancy. She had just returned from a long journey from a distant part of Germany, and had experienced a very rough passage across the channel. On Oct. 8th, 1894, the day after her return to Guildford, severe intermittent pains in the lower part of the abdomen set in. On being called to see her I found the uterus firmly contracted and all the symptoms pointing to an impending abortion. During the next two days there were frequent uterine pains. Perfect rest in bed was enjoined and opiates administered. About 8 A.M. On the morning of the 11th I received an urgent summons to see her, and I asked my friend Mr. Sells of Guildford to accompany me. On our arrival we found that an abortion had taken place and that an immense quantity of blood had been lost. A large chamber utensil was full of clots. The umbilical cord-untied-had slipped up into the vagina. I gave chloroform, and Mr. Sells removed a large number of blood-clots from the vagina, and eventually, but with great diffculty, managed to extract the placenta. The patient was quite blanched from loss of blood, complained of severe abdominal pain, and was in a state of almost total collapse. Ergot and opium were administered freely. Soon after the removal of the placenta the uterus contracted firmly, and no more blood was lost per vaginam. About an hour afterwards, however, the symptoms of shock became more pronounced, and on an examination of the abdomen being made a large mass was found occupying the site of the uterus. It was at first thought that the latter might be distended with clots, and it was accordingly washed out with warm boric solution. Nothing, however, came away. This was puzzling. A closer examination of the lower part of the abdomen revealed a large smooth elastic swelling in the hypogastric region, and on introducing the finger into the vagina a tumour could be distinctly felt pressing on this canal. Mr. Sells and I then came to the conclusion that this could be nothing else than a hæmatocele, due probably to an effusion of blood from some ruptured ressel into the sub-peritoneal tissue around the uterus. A smaller swelling was discovered to the left of the central one-apparently a smaller hrmatocele due to an effusion of blood in the course of the broad ligament. Nothing could be done except to keep the patient perfectly quiet in bed, support her strength, and administer opiates to relieve the pain and restlessness. She remained in an alarmingly weak state for some days, and suffered from profuse perspirations-generally in the early morning-and from frequent attacks of distressing vomiting. The temperature varied from $100^{\circ}$ to $102^{\circ} \mathrm{F}$, and the pulse was very weak and rapid. The smaller swelling cleared up in about a month. Shortly before this disappeared another appeared in the right iliac region and was attended with a good deal of abdominal tenderness and pain and distressing tympanites. The temperature rose to nearly $104^{\circ}$. This was probably an attack of pelvic cellulitis with subacute peritonitis, and it subsided in about a week under the free administration of opium and hot fomentations. The further history of the case-a dreadfully harassing and trying one to the patient and to her attendantsmay be briefly summarised. The prominent symptoms were frequent profuse sweats, distressing irritability of the stomach, obstinate constipation, occasional attacks of severe abdominal pain, and constant tympanites. The temperature generally varied between $100^{\circ}$ and $103^{\circ}$, though sometimes touching $104^{\circ}$, and the pulse was always very rapid-115 to 130-and occasionally of a running character difficult to count. The irritability of the stomach was so great that it was with extreme difficulty she kept down any nourishment. She became reduced to an alarming state of exhaustion and emaciation, and it was only after trying many kinds of food and stimulant that ve succeeded in finding some that could be retainet. These were the only things she could retain, and they enabled her to bear up successfully against her wasting illness. About the beginning of December the tumour, which had never 
shown the slightest sign of any diminution in size, showed signs of enlargement, and indications were soon apparent that matter was forming and was making its way bowards the surface. Soon a good deal of inflammatory thickening and hardness was observable all round the tumour, and it became completely and securely encysted. The pain in it now became agonising. Frequent and strong hypodermic injections of morphia were required. I may here remark that all through this trying case opium was our sheet-anchor. The quantity of it that the patient took by the mouth, by means of suppositories, and by hypodermic injections of morphia was enormous. For three months she was more or less continually under its influence. On Dec. 17th the abscess pointed externally at a spot two inches and a half below and slightly to the left of the umbilicus. The abscess wall could be made out to be adherent to the skin of the abdomen over an area equal to that of a florin. Chloroform having been administered a small incision with a scalpel was made through the skin in the centre of this area. This incision was carefully enlarged with a bistoury on a director, and the lips of the incision were then separated by the blades of a dressing forceps. About a pint of the most terribly fetid dark pus mixed with broken-down blood-clots was evacuated. A drainage-tube was inserted, the wound was dressed twice daily, and for several days the discharge was most copious and offensive, saturating the dressings and causing, by its intolerable odour, great distress to the patient. When the quantity had lessened somewhat the abscess cavity was syringed out twice daily with strong boric solution. This acted excellently. A few hours after the abscess was opened the temperature sank to normal and never afterwards rose above it. Convalescence was uninterrupted. In about six weeks the wound had completely closed. The patient is now in excellent health. The menses-which had been completely suppressed during her long illness-reappeared about the beginning of March.

Guildford.

\section{MODIFICATION OF THE DISTAL LIGATURE FOR ANEURYSMAL DILATATION; A SUGGESTION.}

BY PATRICK J. HAYES, M.D. R.U.I., F.R.C.S. EDIN., SURGEON TO THE MATER MYSERICORDIE HOSPITAL, DUBLIN.

THE majority of hospital surgeons from time to time encounter cases of aneurysm where, the possibility of dealing with the proximal portion of the diseased artery being out of the question, the problem of inducing coagulation within the sac, either by the Brasdor-Wardrop application of ligatures on its distal side or the extremely hazardous introduction through the sac wall of foreign agents, must be considered. I have occasionally observed notable delay with regard to evidence of improvement after distal ligature, and in the case of a thin-walled aneurysm such retardation may -entail rupture of the tense, frail wall where otherwise cure would have been the result of operation. It occurs to my mind that thrombosis can be caused to extend from a distal point rapidly and safely to even a deeply situated aneurysm by such a measure as the following.

The surgeon selects a favourable site for ligaturing the vessel or vessels on the distal side of the aneurysm, and in the event of there being two trunks for ligation he determines which is to be doubly ligatured and divided. Rough measurement of the distance between the aneurysm and the point for double ligature, with division of the artery, is now to be made and a piece of sterilised catgut is to be cut, its length being sufficiently in excess of the measured interval. The arterial trunk having been exposed, a double aseptic silk ligature is passed beneath it and the loop divided so as to leare cords with a space of, say, half an inch between them. The more distal ligature is now to be knotted and its ends removed, but the proximal ligature is to be only loosely tied with a single knot, which will serve merely to moderately compress the arterial walls. It will afford additional help and security if the artery needle be maintained in position beneath the vessel up to the time for tightening the proximal ligature. The next and distinctive step is this: $-\Lambda$ small opening is to be made into the lumen of the artery, midway between the ligatures, and through the aperture a slender cannula, occupied by nearly half the length of aseptic catgut already referred to, is to be introduced and directed towards the proximal or aneurysmal portion of the vessel, until it will have passed just within the part lightly compressed by the proximal ligature. The catgut is now to be gently pushed on through the cannula until the surgeon estimates that its free end will have reached, or perhaps entered, the aneurysmal dilatation. The cannula is then to be withdrawn and the proximal ligature to be firmly tied on the artery corresponding to the distal end of the intraarterial cord of catgut. Subsequently the artery and free part of the catgut are to be cut across at the site of aperture midway between the ligatures. The object attainable by introducing into the lumen of the vessel a bougie of cat gut long enough to reach the sac can be readily understood. The foreign substance must soon become enveloped in a coating of fibrin, and, as it were, act as a gubernaculum for extension of the coagulating process within the aneurysm. At the same time, the sac wall will not have been injured or weakened by any needle puncture, whilst risk of distant embolism will have been guarded against by the previous ligation of the trunk or trunks on the distal side. The question of danger from hæmorrhage during puncture of the artery can easily be answered. The finger and artery needle, supplying points of pressure and counter-pressure, will afford absolute security whilst the opening is being made and the introduction of the cannula being effected. The cannula is well filled by the catgut, so that when the proximal ligature is tightened on its tip little, if any, blood can escape through the instrument. Once a sufficient length of catgut has been introduced the tip of the cannula is withdrawn and the encircling ligature made perfectly tight on the artery containing the clot-determining catgut.

It seems rational to infer that aneurysms, otherwise beyond the reach of surgical treatment, may, with at least comparative safety, have conducted to them thrombi capable of inducing cure by coagulation. Moreover, the catgut, being adapted for solution and absorption under the agency of leucocytes, will, after having effected its purpose, gradually disappear, and with it, in all probability, redundant bloodclot occupying the arterial lumen. Dublin.

\section{Clinital altes:}

MEDICAL, SURGICAL, OBSTETRICAL, AND THERAPEUTICAL.

\section{ERYTHEMATOUS RASH AFTER OPERATION DUE TO} THE ENEMA, NOT TO THE ANESTHETIC.

By H. Belliamy Garderer,

ASSISTANT ANESTHETIST TO CHARING-CROSS HOSPITAL.

AmoNG surgeons of the day there is a very generally prevailing impression that the appearance upon a patient of a red rash after any surgical procedure may be due to the anæsthetic which has been employed. I should like to bring forward a few observations which will tend to relieve the anxsthetic from this accusation. I have now full notes of nine cases of this erythema, occurring chiefly among gynxecological patients, in two London hospitals. The rash is red, raised, almost papular in appearance, arising first about thirty hours after operation on the skin of the thighs and buttocks, then upon the chest, wrists, cheeks, elbows, forearms, and back, preceded and accompanied by a feeling of heat and irritation of the affected part, without pyrexia, lasting two and a half to three days, and fading off subsequently without desquamation. Six of these patients had enemata of hard yellow soap and warm water five hours before operation, when gas and ether were administered to produce anasthesia. One patient, a child, was prepared in the same way and had chloroform as an anxsthetic. Two patients had exactly similar enemata with an exactly similar crythematous rash without the administration of an anasthetic at all. In one of the first six cases the rash became intensified by a second enema given the next day. In another the woman stated she had had an exactly similar rash after an enema four months previously without any use of anæesthetics. 'The child had a slight recurrent rash after a second enema when the first rash had disappeared. Experience of anæisthetics shows that a transitory flush upon the 